e-ISSN : 2597-5234

\title{
PENGARUH BELANJA MODAL, PENDAPATAN ASLI DAERAH, DAN DANA PERIMBAGAN TERHADAP KINERJA KEUANGAN
}

\section{THE EFFECT OF CAPITAL EXPEDITURE, LOCAL REVENUE, AND BALANCE FUNDS ON FINANCIAL PERFORMANCE}

\author{
Novita Sari ${ }^{1}$, Benny Rojeston Marnaek Nainggolan², Rosma Ariyanti Purba ${ }^{3}$, \\ Taruli Br Saragih ${ }^{4}$, Wahy Banjarnahor ${ }^{5}$ \\ Universitas Prima Indonesia, Medan ${ }^{1,2,3,4,5}$ \\ novitas56@yahoo.com ${ }^{1}$
}

\begin{abstract}
The target of this inspection is to investigate the impact of Regional Capital Expenditures and Original Revenues and Balancing Funds on Financial Performance in North Sumatra Province. The technique used in this examination is by obtaining saturated sampling. This examination uses as many samples of 33 districts/cities was used and data were analyzed using the annual financial report (Annual Report) in North Sumatra for the period 2014-2017, which was found through the website www.bps.go.id. This examination wears a model the method of Multiple Linear Regression. Test classic assumptions and hypotheses using the F test and T-test with the SPSS program. The results show capital expenditure, original regional income, and balanced funds that were relevant to financial performance in North Sumatra Province in 2014-2017. Partially, Capital Expenditures and Regional Original Revenue has a relevant impact on Financial Performance. While the Balancing Fund has no significant impact on Financial Performance in North Sumatra Province in 2014-2017.
\end{abstract}

Keywords: Capital Expenditures, Local Own Revenues, Balance Funds, Financial Performance.

\begin{abstract}
ABSTRAK
Target pemeriksaan ini yaitu untuk menyelidiki dampak Belanja Modal Daerah dan Pendapatan Asli Daerah serta Dana Perimbangan terhadap Kinerja Keuangan Provinsi Sumatera Utara. Teknik yang dipakai di pemeriksaan ini dengan perolehan contoh jenuh. Pada pemeriksaan ini digunakan contoh sebanyak 33 kabupaten / kota dan data dianalisis menggunakan laporan keuangan tahunan (Annual Report) di Sumatera Utara periode 2014-2017 yang dapat ditemukan melalui website www.bps.go.id. Pemeriksaan ini memakai model Regresi Linier Berganda. Uji asumsi klasik dan asumsi memakai test $\mathrm{F}$ dan uji-T dengan program SPSS. Perolehan hasil menunjukkan belanja modal, pendapatan asli daerah, dan dana perimbangan relevan dengan kinerja keuangan di Provinsi Sumatera Utara tahun 2014-2017. Secara parsial, Belanja Modal dan Pendapatan Asli Daerah berdampak relevan kepada Kinerja Keuangan. Sedangkan Dana Perimbangan tidak berdampak signifikan terhadap Kinerja Keuangan Provinsi Sumatera Utara tahun 2014-2017.
\end{abstract}

Kata Kunci: Belanja Modal (BM), Pendapatan Asli Daerah (PAD), Dana Perimbangan (DAPER), Kinerja Keuangan (KK). 


\section{PENDAHULUAN}

$\begin{array}{cccc}\text { Pada } & \text { zaman } & \text { sekarang ini, } \\ \text { penerapan } & \text { otonomi } & \text { daerah dan }\end{array}$ penyerahan wewenang secara fiskal mengakibatkan di indonesia akuntansi sektor publik mengalami perkembangan yang semakin cepat. Dengan adanya desentralisasi fiskal diharapkan agar daerah mempunyai kemampuan dengan meningkatkan kelebihan yang dipunyai sebagai daya tarik peminat para investor untuk terjun langsung ke daerah dan membuka usaha, yang meningkatkan pendapatan daerah dan memperbaiki ekonomi masyarakat.

Penilaian kinerja keuangan dapat dinilai dari laporan realialisasi APBD, dikarenakan semakin tinggi belanja modal yang dikonsumsi maka berbanding lurus dengan tingkat produktifitas perekonomian yang tinggi dalam hal kinerja PEMDA.

Kemandirian suatu daerah dapat diukur dengan kemampuan daereh tersebut dalam membiayai setap kegiatan terlebih dalam hal keuangan oleh karena perkembangan pembangunan yang pesat bersumber dari pengalokasian belanja modal yang tepat.

Pendapatan asli daerah (PAD) ialah sesuatu yang dasar dalam mempengaruhi APBD dikarenakan kontribusi PAD Terhadap APBD sangatlah besar, yang apabila Tingkat PAD semakin besar maka suatu daerah yang bergantung kepada pemerintah pusat akan semakin minim.

Dana perimbangan atau dana transfer memiliki fungsi yang sangat penting dalam pencapaian efesiensi dan keseimbangan dalam memberikan layanan jasa publik, dikarenakan berpengaruh terhadap kinerja keuangan dimana pendapatan yang diperoleh dari pusat selalu menggambarkan ketergantungan daerah dalam memenuhi kebutuhannya terhadap pemerintah pusat yang berakibat menurunnya kinerja keuangan (Badruddin, 2017).

Pada pemeriksaan tersebut, Halhal ini akan ditulis peteliti antara lain Belanja Modal, Pendapatan Asli Daerah, dan Dana Perimbangan.

Belanja modal pada tahun 2016 di Kabupaten/Kota Tapanuli Tengah adalah sebesar 169.402.000.000 mengalami penurunan tahun 2017 menjadi sebanyak Rp. 167.521.000.000 tetapi pendapatan asli daerah tahun 2016 sebesar Rp. 1.069.165.000.000 mengalami kenaika di tahun 2017 sebesar Rp. 1.094.022.000.000.

Pendapatan asli daerah pada tahun 2015 di Kabupaten /Kota Tapanuli Selatan adalah sebesar Rp. 109.349.000.000 mengalami penurunan tahun 2016 menjadi sebesar Rp. 76.640.000.000 tetapi pendapatan daerah 2015 sebesar Rp. 1.088.604.000.000 mengalami kenaikan ditahun 2016 sebesar Rp. 1.208.268.000.000.

Dana perimbangan pada tahun 2015 Kabuparen/Kota Karo adalah sebesar Rp. 850.087.000.000 mengalami kenaikan tahun 2016 menjadi sebesar Rp. 1.040.055.000.000 tetapi pendapatan asli daerah tahun 2015 sebesar Rp. 1.470.455.000.000 mengalami penurunan di tahun 2016 sebesar Rp. 1.456.336.000.000.

Halim (2014), tingkat belanja modal (BM) yang tinggi memberikan gambaran dari infrastuktur dan sarana yang yang dibangun. Pada umumnya apabila tingkat pembangunan tinggi, hal tersebut akan meningkatkan pelayanan yang diterima oleh masyarakat yang nantinya akan berdampak baik terhadap kinerja daerah. Hal ini membuktikan, semakin banyak belanja modal maka kemampuan dalam mengukur kinerja keuangan mengalami peningkatan. 


\begin{abstract}
Badjra \& Nyoman (2017), Pendapatan Asli Daerah (PAD) mengungkapkan jika kapasitas suatu daerah dalam menggali PAD apakah berdampak terhadap kemajuan daerah tersebut, Jadi semakin tinggi bantuan PAD kepada APBD, maka semakin minimlah ketergantungan terhadap kontribusi pemerintah pusat. Sedangkan menurut hasil peneitian yang dilakukan Darwanis (2014), Dana Perimbangan (DAPER) mengatakan bahwa pemerintah daerah tidak mampu menggunakan dana dengan baik yang diterima dari pusat, dana perimbangan tidak berdampak kepada kinerja kauangan daerah.
\end{abstract}

Hasil Penelitian menurut Badjra \& Nyoman (2017), belanja modal secara signifikan berpengaruh positif secara tidak langsung terhadap kinerja keuangan melalui Pendapatan Asli Daerah. Pembangunan sarana dan prasarana oleh pemerintah daerah berpengaruh positif pada pertumbuhan ekonomi.

Hasil penelitian ini sejalan dengan penelitian yang dilakukan Halim (2014) dan Nugroho \& Fajar (2012) yang menyatakan bahwa semakin besar Pendapatan Asli Daerah maka belanja daerah juga semakin besar, jika Pendapatan Asli Daerah rendah maka belanja daerah juga akan rendah. Belanja modal secara signifikan berpengaruh secara langsung terhadap kinerja keuangan, dan Belanja modal secara signifikan berpengaruh positif secara tidak langsung terhadap kinerja keuangan melalui Pendapatan Asli Daerah.

Permendagri No. 13 Tahun 2006, pasal 1 ayat 37 Kinerja Keuangan ialah hasil dari tindakan yang sudah ditempuh dengan pemakaian kapasitas dan mutu yang terukur.Kinerja Keuangan pemerintah daerah ialah suatu bentuk yang bisa dipakai dalam memeriksa kapasitas daerah saat melaksanakan kemandirian daerah.

Berdasarkan Uraian fenomena, teori dan penelitian-penelitian yang relevan diatas maka dilakukan penelitian dengan judul "Pengaruh Belanja Modal Pendapatan Asli Daerah dan Dana Perimbangan Terhadap Kinerja Keuangan Kabupaten/Kota Di Provinsi Sumatera Utara 2014-2017”.

\section{METODE PENELITIAN}

Penelitian ini dibuat di Provinsi Sumatera Utara. Pemeriksaan ini dibuat untuk memeriksa benarkah belanja modal, pendapatan asli daerah, dan dana perimbangan berpengaruh terhadap kinerja keuangan pada Kabupaten/Kota Sumatera Utara periode 2014-2017. Penelitian ini memakai metode kuantitatif bertujuan untuk mengetahui pengaruh dari variabel bebas yakni belanja modal, pendapatan asli daerah dan dana perimbangan terhadap variabel dependenya yaitu kinerja keuangan. Model data yang dipakai ialah data sekunder yang didapat di Badan Pusat Statistik (BPS) periode 2014-2017.

Populasi yang dipakai di pemeriksaan ini yaitu semua kabupaten disumatera utara yaitu sebanyak 33 kabupaten/kota. Teknik pengambilan sampel yaitu teknik perposive sampling.

Metode analisis data yang dipakai ialah teknik analisis statistic. Saat data belum diperiksa, maka kepentingan data analisis tersebut lebih dulu dibuat uji asumsi klasik sebelum pembuatan uji hipotesis. Analisis data dalam mengelola data mengunakan SPSS ( Statistical Product And Service Sol Solution). Bentuk analisis data ini menggunakan analisis regresi berganda agar dapat diketahui pengaruh variabel bebas (indevenden) dan variabel terikat (dependen) digunakan rumus analisis regresi linear berganda sebagai berikut : 


\section{$\mathrm{Y}: \mathrm{a}+\mathrm{b} 1 \mathrm{X} 1+\mathrm{b} 2 \mathrm{X} 2+\mathrm{b} 3 \mathrm{X} 3 \mathrm{e}$}

Keterangan :

$\mathrm{Y}=$ Kinerja keuangan

$\mathrm{a}=$ Konstanta

$\mathrm{b} 1=$ Koefisien regresi variabel X1 (belanja Modal)

$\mathrm{b} 2=$ koefisien regresi variabel $\mathrm{X} 2 \quad($

Pendapatan Asli Daerah)

$\mathrm{B} 3$ = koefisien regresi variabel X3 ( Dana Perimbangan)

$\mathrm{X} 1=$ variabel belanja modal

$\mathrm{X} 2=$ variabel pendapatan asli daerah

$\mathrm{X} 3=$ variabel dana perimbangan

$\mathrm{e}=$ persetase kesalahan $(0,05)$

\section{HASIL DAN PEMBAHASAN}

Uji signifikansi secara parsial ( $T$ Test )

Uji statistik parsial dibuat untuk memahami bagaimana pengaruh variabel bebas sebagai individual ke variabel terikat. Pemeriksaan ini dibuat dengan cara membedakan antara nilai $t_{\text {hitung }}$ dengan $t_{\text {tabel }}$.

Tabel 1 Hasil Pengujian Statistik Uji t

\begin{tabular}{llllll}
\hline \multicolumn{6}{c}{ Unstandardized Standardized } \\
Coefficients & Coefficients & \\
\hline Model & B & $\begin{array}{l}\text { Std. } \\
\text { Error }\end{array}$ & Beta & T & Sig. \\
\hline 1 (Constant) $)$ & 2.902 & .747 & & 3.886 & .000 \\
\hline LN_BM & -.058 & .029 & -.180 & -2.029 & .045 \\
\hline LN_PAD & -.109 & .015 & -.689 & -7.212 & .000 \\
\hline LN DAPER .038 & .039 & .098 & .961 & .339 \\
\hline \multicolumn{5}{c}{ Sumber : Hasil Pengolaan Data, 2019 } \\
\hline
\end{tabular}

Nilai $t_{\text {tabel }}$ untuk probabilitas 0,05 pada derajat bebas 128 iaalah sebanyak 1,978. Jadi, hasil uji t dapat dirangkum antara lain:

1. Penjumlahan uji $\mathrm{t}$ segmental didapat nilai $t_{\text {hitung }}$ belanja modal sebanyak 2,029 dengan angka relevan sebanyak 0,045. Angka $-t_{\text {hitung }}<-$ $t_{\text {tabel }}$ dan $-2,029<-1,978$. Maka $\mathrm{H}_{\mathrm{a}}$ diterima dan $\mathrm{H}_{0}$ ditolak berarti belanja modal berpengaruh sangat jelas dan penting terhadap kinerja keuangan.
2. Didapatkan penjumlahan uji t secara segmental ditemukan angka thitung Pendapatan Asli Daerah sebanyak 7,212 dengan angka signifikan sebesar 0,000. Angka $-t_{\text {hitung }}<-t_{\text {tabel }}$ dan $-7,212<-1,978$. Jadi $\mathrm{H}_{\mathrm{a}}$ diterima dan $\mathrm{H}_{0}$ ditolak dimana Pendapatan Asli Daerah berdampak positif dan signifikan ke kinerja keuangan.

3. Ditemukan jumlah uji $t$ secara segmental didapat angka thitung Dana Perimbangan sebanyak 0,961 angka signifikan sebanyak 0,339. Angka $t_{\text {hitung }}>t_{\text {tabel }}$ dan $0,961>1,978$. Jadi $\mathrm{H}_{\mathrm{a}}$ ditolak dan $\mathrm{H}_{0}$ diterima dimana Dana Perimbangan tidak berdampak positif lalu tidak singnifikan kepada kinerja keuangan.

\section{Uji Signifikansi Secara Simultan (F- Test)}

Test $\mathrm{F}$ merupakan uji yang dipakai dalam memahami bagaimana pengaruh atau hubungan antara seluruh variabel independen secara serentak kepada variabel parsial dan benarkah teknik regresi yang dipakai bersifat signifikan/baik atau non signifikan/tidak baik.

Tabel 2 Hasil Pengujian Secara Simultan Uji

F

\begin{tabular}{|c|c|c|c|c|c|}
\hline Model & $\begin{array}{l}\text { Sum } \\
\text { Squares }\end{array}$ & Df & $\begin{array}{l}\text { Mean } \\
\text { Square }\end{array}$ & $\mathrm{F}$ & Sig. \\
\hline 1 Regression & 1.6351 & 3 & .545 & 52.823 & $.000^{\mathrm{b}}$ \\
\hline Residual & 1.321 & 128 & .010 & & \\
\hline Total & 2.956 & 131 & & & \\
\hline
\end{tabular}

Sumber : Hasil Pengolaan Data, 2019

Uji signifikan simultan/ berhubungan ( uji statistik F ) mendapat

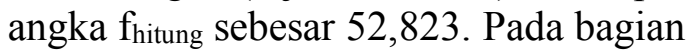
bebas $1\left(\mathrm{df}_{1}\right)=\mathrm{k}-1=4-1=3$, dan derajat bebas $2\left(\mathrm{df}_{2}\right)=\mathrm{n}-(\mathrm{k}-1)=132$ $-(3-1)=128$, nilai $\mathrm{f}$ table pada angka keyakinan penerimaan 0,05 adalh 2,68. Jadi, $F_{\text {hitung }} 52,823>\mathrm{F}_{\text {tabel }}=2,68$ dengan angka signifikan $0,000<0,05$. Jadi $\mathrm{H}_{\mathrm{a}}$ diterima $\mathrm{H}_{0}$ ditolak dimana secara 
berkelompok variabel belanja modal, pendapatan asli daerah, dan dana perimbangan berdampak dan signifikan ke kinerja keuangan .

Hubungan dari Uraian fenomena, teori-teori dan penelitianpenelitian yang relevan diatas dengan ketiga variabel yand diteliti memperoleh hasil secara parsial yang menunjukkan bahwa Belanja Modal dan Pendapatan Asli Daerah berdampak relevan kepada Kinerja Keuangan. Sedangkan Dana Perimbangan tidak berdampak signifikan terhadap Kinerja Keuangan Provinsi Sumatera Utara tahun 20142017. Hal ini sejalan dengan penelitian Mulyani (2017) dan Pratiwi (2020).

\section{PENUTUP}

\section{Kesimpulan}

1. Belanja Modal secara parsial berdampak secara relevan ke Kinerja Keuangan di Pemerintah Kabupaten/Kota di Sumatera Utara periode 2014-2017.

2. Pendapatan Asli Daerah secara segmental berdampak ke Kinerja Keuangan pada Pemerintah Kabupaten/Kota di Sumatera Utara Tahun 2014-2017.

3. Dana Perimbangan secara parsial berdampak dan penting ke Kinerja Keuangan pada Pemerintah Kabupaten/Kota di Sumatera Utara Tahun 2014-2017.

4. Belanja Modal, Pendapatan Asli Daerah dan Dana Perimbangan dengan serentak berpengaruh dan relevan ke Kinerja Keuangan pada Pemerintah Kabupaten/Kota di Sumatera Utara Tahun 2014-2017. Koefisien determinasi sebesar $54,3 \%$.

\section{Saran}

Bagi peneliti seterusnya diberi masukan untuk memperbanyak tahun penelitian dan meningkatkan sampel yang akan diperiksa, sehingga hasil yang didapatkan dapat dipakai sebagai hasil pemeriksaan kinerja keuangan pemerintah kabupaten dan kota di Provinsi Sumatera Utara.

\section{DAFTAR PUSTAKA}

Halim, A. (2014). Manajemen Keuangan Sektor Publik, Jakarta: Salemba Empat.

Badruddin, R. (2017). Ekonomika Otonomi Daerah, Yogjakarta: Upp STIM YKPN.

Mulyani, S. (2017). Pengaruh Belanja Modal, Ukuran Pemerintah Daerah, Intergovernmental revenue dan PAD Terhadap Kinerja Keuangan. Kompertemen, 18 (1) 1-10.

Darwanis, R., Saputra. (2014). Pengaruh Belanja Modal terhadap PAD dan Dampaknya terhadap Kinerja Keuangan Pemerintah Daerah, Jurnal Dinamika Akuntansi dan Bisnis, 1 (2) 183-199.

Badjra, B., Ida., Ketut., Mustanda, \& Nyoman, A. (2017). Kontribusi Pendapatan Asli Daerah dan Dana Perimbangan terhadap Belanja Modal dan Kinerja Keuangan, Jurnal Akuntansi Indonesia, 6 (1) 29-40.

Pratiwi, N., Diva (2020). Pengaruh Pendapatan Asli Daerah, Dana Perimbangan, Dana Keistimewaan, dan Belanja Modal terhadap Kinerja Keuangan Pemerintah Daerah, Jurnal Kajian Bisnis. 28(1): 8910

Nugroho, F \& Abdul, R. (2012). Pengaruh Belanja Modal Terhadap Pertumbuhan Kinerja Keuangan Daerah Dengan Pendapatan Asli Daerah Sebagai Variabel Intervening (Studi Kasus Di Propinsi Jawa Tengah) 